\title{
Influence of Surface Passivation on Perovskite CsPbBr1.2l1.8 Quantum Dots and Application of High Purity Red Light-Emitting Diodes
}

\section{Lung-Chien Chen ( $\sim$ ocean@ntut.edu.tw)}

National Taipei University of Technology https://orcid.org/0000-0001-5470-8491

Yen-Hung Tien

National Taipei University of Technology

Jianjun Tian

University of Science and Technology Beijing

\section{Research Article}

Keywords: Perovskite quantum dots, Trioctylphosphine oxide, Lead nitrate, Light-emitting diodes

Posted Date: August 12th, 2021

DOI: https://doi.org/10.21203/rs.3.rs-796798/v1

License: (c) (i) This work is licensed under a Creative Commons Attribution 4.0 International License.

Read Full License

Version of Record: A version of this preprint was published at Journal of Alloys and Compounds on February 1st, 2022. See the published version at https://doi.org/10.1016/j.jallcom.2021.162140. 


\section{Abstract}

In this work, trioctylphosphine oxide (TOPO) ligand is employed to improve the quality of $\mathrm{CsPbBr} \mathrm{Pb}_{1.2} \mathrm{I}_{1.8}$ quantum dots (QDs) films. Lead nitrate $\left(\mathrm{Pb}\left(\mathrm{NO}_{3}\right)_{2}\right)$ is also used to passivate the surface of the films. The study of ligand and surface passivation on the luminous efficiency of red light-emitting diode (LED) is discussed. The CsPbBr ${ }_{1.2} \mathrm{I}_{1.8}$ QDs films co-doped with TOPO and $\mathrm{Pb}\left(\mathrm{NO}_{3}\right)_{2}$ can effectively improve the performance of the $\mathrm{CsPbBr}_{1.2} \mathrm{I}_{1.8}$ QDs LEDs due to reduction of non-radiation recombination of the carriers and smooth morphology in the active layer, thus improving the injection and transportation capabilities of carriers. As a result, the highest luminosity and current efficiency are $502.7 \mathrm{~cd} / \mathrm{m}^{2}$ and $0.175 \mathrm{~cd} / \mathrm{A}$, respectively.

\section{Introduction}

Perovskite is a mineral composed of calcium, titanium and oxygen, and its chemical formula is $\mathrm{CaTiO}_{3}$ [1]. Any compound represented by the general formula ABX3 can be called perovskite. Material of A site can be divided into all-inorganic perovskite and organic-inorganic mixed type perovskite. $A$ is a monovalent inorganic cation. It is composed of $\mathrm{Cs}^{+}$. A can also be composed of monovalent organic cations, such as $\mathrm{CH}_{3} \mathrm{NH}_{3}{ }^{+}$(methylammonium, $\mathrm{MA}^{+}$) or $\mathrm{CH}\left(\mathrm{NH}_{2}\right)_{2}{ }^{+}$(formamidinium, $\mathrm{FA}^{+}$), $\mathrm{B}$ is composed of divalent metal cations, usually lead ion $\mathrm{Pb}^{2+}$ or tin ion $\mathrm{Sn}^{2+}$, and $\mathrm{X}$ is a halogen anion, mainly $\mathrm{Cl}^{-}, \mathrm{Br}^{-}$or $1-[2-5]$. By controlling the combination and ratio of $A, B$, and $X$, different optical properties can be adjusted. $\mathrm{MAPbX}_{3}$ and $\mathrm{CsPbX}_{3}$ active layer in device structure mainly used in solar cells, photodetectors, optoelectronic devices, and light-emitting diodes (LEDs) [6-14].

Surface passivation is an effective method to protect the surface of the perovskite film, reduce the charge traps caused by structural defects, and prevent the surface from being affected by moisture in the air, and improve its luminous efficacy. Several articles have reported the effects of surface passivation on the optical and electrical properties of materials, and demonstrated enhanced luminescence properties by inhibiting non-radiative recombination and reducing defect states [15-18]. Polyhedral siloxane oligomers (POSS) serve as a useful passivation layer. POSS-coated perovskite quantum dot light-emitting diodes improve water resistance or poor solvent resistivity and film-forming ability. The brightness and stability of light-emitting diodes treated with POSS are improved [19]. The tri-n-octyl phosphine oxide (TOPO) is passivated on the surface of the perovskite $\mathrm{FAPbBr}_{3}$ film to reduce the non-radiative recombination on the surface of the perovskite or the grain boundary [20]. After using $\mathrm{AX}\left(\mathrm{A}=\mathrm{FA}^{+}, \mathrm{MA}^{+}\right.$or $\mathrm{Cs}^{+}$, and $\mathrm{X}=\mathrm{Br}^{-}$or $\left.\mathrm{I}^{-}\right)$to treat the surface of the $\mathrm{CsPbl}_{3}$ perovskite film, it greatly improves the electronic coupling between quantum dots, thereby enhancing carrier transportation rate [21]. This work studies the characteristics of all-inorganic perovskite $\mathrm{CsPbBr}{ }_{1.2} 1_{1.8}$ QDs with TOPO and $\mathrm{Pb}\left(\mathrm{NO}_{3}\right)_{2}$ surface passivation treatment. And, the $\mathrm{CsPbBr}{ }_{1.2} \mathrm{I}_{1.8}$ QDs films with TOPO and $\mathrm{Pb}\left(\mathrm{NO}_{3}\right)_{2}$ were used as the active layer to examine the optoelectronic properties of red light-emitting diodes (LEDs). 


\section{Experiments}

\subsection{Preparation of $\mathrm{CsPbBr}_{1.2} \mathrm{I}_{1.8}: \mathrm{TOPO}$ solution}

First of all, $0.132 \mathrm{M}$ cesium carbonate $\left(\mathrm{Cs}_{2} \mathrm{CO}_{3}\right), 20 \mathrm{~mL}$ octadecene (ODE), and $1.25 \mathrm{~mL}$ oleic acid (OA) were added into a $50 \mathrm{~mL}$ beaker $\mathrm{A}$, and heated it at $120^{\circ} \mathrm{C}$ for $1 \mathrm{hr}$. The temperature was then increased to $150^{\circ} \mathrm{C}$ for $15 \mathrm{~min}$ to make the cesium carbonate and oleic acid react completely, and the solution appeared light yellow color. Next, TOPO with different density $(1.0,0.2$, and $0.4 \mathrm{mmol}), 0.3 \mathrm{mmol}$ of lead bromide $\left(\mathrm{PbBr}_{2}\right), 0.45 \mathrm{mmol}$ of lead iodide $\left(\mathrm{Pbl}_{2}\right), 20 \mathrm{~mL}$ of octadecene (ODE), $2 \mathrm{~mL}$ of oleic acid (OA), and $2 \mathrm{~mL}$ of oleylamine (OAm) were added into a $50 \mathrm{~mL}$ beaker $\mathrm{B}$, and heat it at $120^{\circ} \mathrm{C}$ for $1 \mathrm{hr}$. Then, the temperature raised up to $180^{\circ} \mathrm{C}$ for $10 \mathrm{~min}$. Taking $1.6 \mathrm{~mL}$ from the beaker $A$ added into the beaker $B$, quickly. After $5 \mathrm{sec}$, the beaker B was put into an ice bath to stop the reaction of the quantum dot solution. After $1 \mathrm{~min}$, take it out to complete the preparation of $\mathrm{CsPbBr}_{1.2} \mathrm{l}_{1.8}: \mathrm{TOPO}$ perovskite quantum dot precursor.

\subsection{Procedure of LEDs}

The LED structure in this work is deposited PEDOT:PSS hole injection layer, poly-TPD hole transporting layer, $\mathrm{CsPbBr}{ }_{1.2} \mathrm{l}_{1.8}: \mathrm{TOPO}$ perovskite QD emitting layer, TPBi electron transport layer, and Ag anode on the ITO glass substrate with electrode pattern in this order. The PEDOT:PSS solution was deposited onto the ITO glass substrate with electrode pattern by spin coating at $5000 \mathrm{rpm}$ for $60 \mathrm{~s}$ and baked at $120^{\circ} \mathrm{C}$ for $20 \mathrm{~min}$ to form a hole injection layer. The ITO glass substrates with electrode pattern were washed in an ultrasonic cleaner with deionized water, acetone, and isopropyl alcohol for $30 \mathrm{~min}$ before to deposit the PEDOT:PSS films. The hole transporting layer was formed by spin-coating poly-TPD chlorobenzene solution (12 $\left.\mathrm{mg} \mathrm{mL}^{-1}\right)$ at $6000 \mathrm{rpm}$ for $60 \mathrm{~s}$ and baking at $100^{\circ} \mathrm{C}$ for $10 \mathrm{~min}$. Sequentially, CsPbBr ${ }_{1.2} \mathrm{I}_{1.8}:$ TOPO perovskite QD emitting layer was formed by spin coating at $2000 \mathrm{rpm}$ for $60 \mathrm{~s}$ followed by annealing at $100^{\circ} \mathrm{C}$ for $5 \mathrm{~min}$. Finally, the 40-nm-thick TPBi electron transport layer and 100$\mathrm{nm}$-thick $\mathrm{Ag}$ anodes were deposited by thermal evaporation under a high vacuum of $5 \times 10^{-6}$ Torr. The active area of the device was approximately $2 \mathrm{~mm} \times 2 \mathrm{~mm}$. After fabrication, the $\mathrm{CsPbBr}_{1.2} \mathrm{l}_{1.8}$ perovskite LEDs were encapsulated using UV glue and a glass cover in a glove box. The typical diagram of the perovskite quantum dot LED is shown in Figure 2.

\subsection{Characterization}

Transmission Electron Microscope (TEM) was employed to observed the particle size distribution of perovskite quantum dots (QDs). Morphologies of the $\mathrm{CsPbBr}_{1.2} \mathrm{I}_{1.8}$ QDs were observed using a fieldemission scanning electron microscope (FESEM, ZEISS Sigma, ZEISS, Munich, Germany). X-ray diffraction (XRD) patterns were characterize using X-ray diffractometer (X'Pert PRO MRD, PANalytical, Almelo, Netherlands). The photoluminescence (PL) spectra were recorded by fluorescence spectrophotometer (F-7000, Hitachi, Tokyo, Japan). The characteristic of LEDs, such as light output 
power, electroluminescence, and current-voltage $(I-V)$, were measured using PR-670 spectroradiometer and Keithley 2420 sourcemeter.

\section{Results And Discussion}

Figure 3 shows TEM images of $\mathrm{CsPbBr}_{1.2} \mathrm{I}_{1.8}$ QDs mixed with various concentration of TOPO. Obviously, the size distribution of QD particles appeared barely change, but condensation and compact as the concentration of TOPO added into the solution of $\mathrm{CsPbBr}_{1.2} \mathrm{I}_{1.8}$ QDs increases due to self-aggregation effect $[22,23]$.

Figure 4(a) plots the photoluminescence (PL) spectra of $\mathrm{CsPbBr}_{1.2} \mathrm{I}_{1.8}$ QDs mixed with various concentration of TOPO. The PL peak position of all samples is around $652 \mathrm{~nm}$. With the increase of the concentration of TOPO, the intensity of PL spectrum increases. The spectrum of sample of $\mathrm{CsPbBr}{ }_{1.2} \mathrm{I}_{1.8}$ mixed with 0.4 mmole TOPO exhibits the strongest intensity and narrowest FWHM $(28 \mathrm{~nm})$, respectively. It may be attributed to the more condense of QDs as concentration of TOPO increases, as shown in Fig. 3. Another factor is the reduction of surface defects of $\mathrm{CsPbBr}_{1.2} \mathrm{I}_{1.8}$ QDs after passivation treatment with TOPO [24]. Figure 4(b) plots the absorbance of spectra of $\mathrm{CsPbBr}_{1.2} \mathrm{I}_{1.8}$ QDs mixed with various concentration of TOPO. The absorbance spectra are cut-off at $\sim 650 \mathrm{~nm}$ for all samples. It consists with the PL spectra.

Figure 5(a)-(d) display top-view FESEM images of $\mathrm{CsPbBr}_{1.2} \mathrm{l}_{1.8}$ films mixed with various concentration of TOPO. As shown in Fig. 5(a), the morphology of TOPO-free $\mathrm{CsPbBr}_{1.2} \mathrm{I}_{1.8}$ film appears some holes and incomplete. However, a complete $\mathrm{CsPbBr}_{1.2} \mathrm{l}_{1.8}$ film was formed when the 0.2 mmole TOPO was added into QDs solution. It may be contributed to the self-aggregation effect of TOPO, as shown in Fig. 5(c) and (d) $[22,23]$. Although the coverage and compact are improved by using TOPO, the height difference on the surface of $\mathrm{CsPbBr}{ }_{1.2} 1_{1.8}: \mathrm{TOPO}$ film is great owing to the reaction rate. In this work, $\mathrm{Pb}\left(\mathrm{NO}_{3}\right)_{2}$ was employed to improve the morphology and to smooth the $\mathrm{CsPbBr}_{1.2} \mathrm{I}_{1.8}: \mathrm{TOPO}$ perovskite QDs film, as shown in Fig. $5(\mathrm{e})$, because $\mathrm{Pb}\left(\mathrm{NO}_{3}\right)_{2}$ can suppress and slow down the growth of perovskite QD film $[25,26]$. The surface passivation and growth rate reduction can promote the crystalline quality of $\mathrm{CsPbBr}_{1.2} \mathrm{l}_{1.8}$ perovskite QDs films. As shown in Fig. 5(f), the peak locations of XRD patterns mostly same. All samples exhibit a typical cubic phase, the high pure a-phase is obtained with two main peaks at $14.6^{\circ}$ and $29.5^{\circ}$, corresponding to the (100) and (200) planes of cubic phase, respectively $[27,28]$. Obviously, the $\mathrm{CsPbBr}_{1.2} \mathrm{I}_{1.8}: \mathrm{TOPO}(0.2$ and 0.4 mmole) films show a decreased full width at halfmaximum (FWHM) for the (200) peak in comparison with TOPO-free film. It suggests increased crystallite size and decreased surface defect $[27,29]$, in well agreement with the PL spectra mentioned above. In addition, no peaks were newly formed, disappeared or shifted, implying that the perovskite crystal structure did not change during TOPO and $\mathrm{Pb}\left(\mathrm{NO}_{3}\right)_{2}$ passivation treatment.

Figure 6 shows the atomic force microscope (AFM) images of the CsPbBr $\left.{ }_{1.2}\right|_{1.8}$ QDs film. Ra is the average roughness and $\mathrm{Rz}$ is the difference between the highest point and the lowest point on the surface 
of film. For the CsPbBr${ }_{1.2} 1_{1.8}$ :TOPO (0.2 mmole) film without surface passivation using $\mathrm{Pb}\left(\mathrm{NO}_{3}\right)_{2}$, Ra and $\mathrm{Rz}$ are 15.2 and $123.8 \mathrm{~nm}$, respectively. However, for the $\mathrm{CsPbBr}_{1.2} \mathrm{1}_{1.8}: \mathrm{TOPO}(0.2 \mathrm{mmole})$ film with surface passivation using $\mathrm{Pb}\left(\mathrm{NO}_{3}\right)_{2}, \mathrm{Ra}$ and $\mathrm{Rz}$ are 2.7 and $24.8 \mathrm{~nm}$, respectively. The surface of the film with treatment of $\mathrm{Pb}\left(\mathrm{NO}_{3}\right)_{2}$ is relatively smooth.

Structure of $\mathrm{CsPbBr}_{1.2} \mathrm{I}_{1.8}$ perovskite QDs LED is shown in Fig 7. The function of ITO, PEDOT:PSS PolyTPD, QDs, and TPBi is anode, hole transport layer, hole injection layer, active layer, and electron transport layer, respectively. Figure 8(a) sketches the band structure of $\mathrm{CsPbBr}_{1.2} \mathrm{I}_{1.8}$ perovskite QDs LED. Poly-TPD and TPBi layers can effectively confine carriers in the structure.

As shown in Fig. 8(b), the peak range of electroluminescence (EL) spectra of $\mathrm{CsPbBr}_{1.2} \mathrm{l}_{1.8}$ perovskite QDs LED is from 668 to $671 \mathrm{~nm}$. The variation may be contributed to error of measurement or process. The EL spectrum has a red shift of $20 \mathrm{~nm}$ compared with the PL spectrum. It may be contributed to the heat caused by resistance of materials in the LED structures. As shown in Figure 8(c), the brightness of $\mathrm{CsPbBr}_{1.2} \mathrm{I}_{1.8}$ QDs LED doped with TOPO increases with the concentration of TOPO doping due to surface passivation and reducing non-radiative recombination in the perovskite active layer [24]. However, excessive TOPO will result in a decrease in brightness. The $\mathrm{CsPbBr}_{1.2} \mathrm{I}_{1.8}$ QDs LED doped with TOPO: 0.2 mmole shows a better luminous brightness with a luminosity of $437.2 \mathrm{~cd} / \mathrm{m}^{2}$ (@9.5 V)

In the next phase, $\mathrm{Pb}\left(\mathrm{NO}_{3}\right)_{2}$ was employed to add into the solution of perovskite:TOPO to improve the morphology and uniformity of active layer according to the AFM images, as shown in Fig. 6 . The current efficiency and luminosity is $0.175 \mathrm{~cd} / \mathrm{A}$ and $502.7 \mathrm{~cd} / \mathrm{m}^{2}$, respectively (@11 V). The improvement is caused by slow formation rate of perovskite active layer, such that reduction of leakage current [30-32]. As shown in Fig. 8(f), after 14-days burn-in test, the $\mathrm{CsPbBr}_{1.2} \mathrm{l}_{1.8}$ QDs LED with doped TOPO: 0.2 mmole and $\mathrm{Pb}\left(\mathrm{NO}_{3}\right)_{2}$ shows the best luminance owing to the surface passivation and smooth surface of the active layer.

Figure 9 shows $\mathrm{CIE}$ chromaticity diagram of $\mathrm{CsPbBr}_{1.2} \mathrm{I}_{1.8}$ with $\left(\mathrm{TOPO}, \mathrm{Pb}\left(\mathrm{NO}_{3}\right)_{2}\right)$. The inset is the photo with $10 \mathrm{~V}$ bias in the dark. The coordinates of $\mathrm{CIE}$ chromaticity diagram are $(0.738,0.2905)$. It is very close to the boundary CIE chromaticity diagram. The advantage of this work is that red-light color is very pure due to good uniformity of the perovskite active layer. It is suitable for the application of display technology.

\section{Conclusions}

In this study, the $\left.\mathrm{CsPbBr}{ }_{1.2}\right|_{1.8}$ perovskite QDs were synthesized by thermal injection method. TOPO was doped into the traditional combination of $\mathrm{OA}$ and $\mathrm{OAm}$ ligands with three different concentrations. According to the PL spectra, it can be observed that the wavelength intensity of QDs increases with increase of the addition amount of TOPO. The LED based on QD with TOPO (0.2 mmole) and $\mathrm{Pb}\left(\mathrm{NO}_{3}\right)_{2}$ showed much higher brightness than that of the control device. $\mathrm{Pb}\left(\mathrm{NO}_{3}\right)_{2}$ can improve the surface 
passivation of the $\mathrm{CsPBr}_{1.2} \mathrm{I}_{1.8}$ :TOPO layers. The quality of the film is improved according to the results of TEM and AFM images. The surface of the film is flat and the transportation of the electron transport layer and the light-emitting layer is enhanced. The coordinate of CIE chromaticity diagram is very close to the boundary. The advantage of this work is that red-light color is very pure due to good uniformity of the perovskite active layer. In the future, it is suitable for the application of display technology.

\section{Declarations}

\section{Declaration of interest}

None declared.

\section{Acknowledgments}

This work was supported by the Ministry of Science and Technology (Taiwan) under contract Nos. 1092622-E-027-093 and 110-2221-E-027-125. This work was also supported by NTUT-USTB joint research program under contract No. NTUT-USTB-107-08.

\section{References}

1. Z. Cheng, J. Lin, Layered organic-inorganic hybrid perovskites: structure, optical properties, film preparation, patterning and templating engineering, Cryst. Eng. Comm. 12(2010)2646-2662.

2. S. T. Ha, R. Su, J. Xing, Q. Zhang, Q. Xiong, Metal halide perovskite nanomaterials: synthesis and applications, Chem. Sci. 8(2017)2522-2536.

3. J. S. Manser, J. A. Christians, P. V. Kamat, Intriguing optoelectronic properties of metal halide perovskites, Chem. Reviews 116(2016)12956-13008.

4. Y. Zhao, K. Zhu, Organic-inorganic hybrid lead halide perovskites for optoelectronic and electronic applications, Chem. Soc. Reviews 45(2016)655-689.

5. Z. J. Shi, J. Guo, Y. H. Chen, Q. Li, Y. F. Pan, H. J. Zhang, Y. D. Xia, W. Huang, Lead-free organicinorganic hybrid perovskites for photovoltaic applications: recent advances and perspectives, Adv. Mater. 29(2017)1605005.

6. A. D. Taylor, Q. Sun, K. P. Goetz, Q. Z. An, T. Schramm, Y. Hofstetter, M. Litterst, F. Paulu, Y. Vaynzof, A general approach to high-efficiency perovskite solar cells by any antisolvent, Nat. Comm. 12(2021)1878.

7. Y. Yang, C. Liu, A. Mahata, M. Li, C. Roldán-Carmona, Yong Ding, Z. Arain, W. D. Xu, et al., Universal approach toward high-efficiency two-dimensional perovskite solar cells via a vertical-rotation process, Energy Enviro. Sci. 13(2020)3093-3101.

8. Q. Zhao, A. Hazarika, X. H. Chen, S. P. Harvey, B. W. Larson, G. R. Teeter, J. Liu, et. al., High efficiency perovskite quantum dot solar cells with charge separating heterostructure, Nat. Comm. 10(2019)2842. 
9. E. D. Gaspera, Y. Peng, Q. C. Hou, L. Spiccia, Udo Bach, J. J. Jasieniak, Y. B. Cheng, Ultra-thin high efficiency semitransparent perovskite solar cells, Nano Energy 13(2015)249-257.

10. Z. Q. Zhang, K. Chen, W. Xia, Z. Y. Zuo, $\mathrm{MAPbBr}_{3}$ single crystal based metal-semiconductor-metal photodetector enhanced by localized surface plasmon, Mater. Res. Express 7(2020)125902.

11. L. C. Chen, K. L. Lee, K. Y. Lee, Y. W. Huang, R. M. Lin, Study of Metal-Semiconductor-Metal $\mathrm{CH}_{3} \mathrm{NH}_{3} \mathrm{PbBr}_{3}$ Perovskite Photodetectors Prepared by Inverse Temperature Crystallization Method, Sensors 20(2020)297.

12. T. K. Zhang, M. Z. Long, L. X. Pan, K. H. Ngai, M. C. Qin, F. Y. Xie, X. H. Lu, J. Chen, J. B. Xu, Green perovskite light-emitting diodes with simultaneous high luminance and quantum efficiency through charge injection engineering, Sci. Bull. 65(2020)1832-1839.

13. L. C. Chen, C. H. Tien, Z. L. Tseng, J. H. Ruan, Enhance efficiency of MAPbI3 perovskite solar cells with $\mathrm{FAPbX}_{3}$ perovskite quantum dots, Nanomater. 9(2019)121.

14. N. N. Wang, L. Cheng, R. Ge, S. T. Zhang, Y. F. Miao, W. Zou, C. Yi, et. al., Perovskite light-emitting diodes based on solution-processed self-organized multiple quantum wells, Nat. Photon. 10(2016)699-704.

15. M. Kim, S. G. Motti, R. Sorrentino, A. Petrozza, Enhanced solar cell stability by hygroscopic polymer passivation of metal halide perovskite thin film, Energy Environ. Sci. 11(2018)2609-2619.

16. H. Zhang, Y. Z. Wu, C. Shen, E. P. Li, C. X. Yan, W. W. Zhang, H. Tian, L. Y. Han, W. H. Zhu, Efficient and stable chemical passivation on perovskite surface via bidentate anchoring, Adv. Energy Mater. 9(2019)1803573.

17. L. J. Zuo, H. X. Guo, D. W. deQuilettes, S. Jariwala, N. De Marco, S. Q. Dong, R. DeBlock, D. S. Ginger, Bruce Dunn, M. K. Wang, Y. Yang, Polymer-modified halide perovskite films for efficient and stable planar heterojunction solar cells, Sci. Adv. 3(2017)1700106.

18. Q. Jiang, Y. Zhao, X. W. Zhang, X. L. Yang, Y. Chen, Z. M. Chu, Q. F. Ye, X. X. Li, Z. G. Yin, J. B. You, Surface passivation of perovskite film for efficient solar cells, Nat. Photon. 13(2019)460-466.

19. H. Huang, H. Lin, S. V. Kershaw, A. S. Susha, W. C. Choy, A. L. Rogach, Polyhedral oligomeric silsesquioxane enhances the brightness of perovskite nanocrystal-based green light-emitting devices, J. Phys. Chem. Lett. 7(2016)4398-4404.

20. X. L. Yang, X. W. Zhang, J. X. Deng, Z. M. Chu, Q. Jiang, J. H. Meng, P. Y. Wang, L. Q. Zhang, Z. G Yin, J. B. You, Efficient green light-emitting diodes based on quasi-two-dimensional composition and phase engineered perovskite with surface passivation, Nat. Commun. 9(2018)1-8.

21. E. M. Sanehira, A. R. Marshall, J. A. Christians, S. P. Harvey, P. N. Ciesielski, L. M. Wheeler, P. Schulz, L. Y. Lin, M. C. Beard, J. M. Luther, Enhanced mobility $\mathrm{CsPbl}_{3}$ quantum dot arrays for record-efficiency, high-voltage photovoltaic cells, Sci. Adv. 3(2017)4204.

22. O. O. Matvienko, Y. N. Savin, A. S. Kryzhanovska, O. M. Vovk, M. V. Dobrotvorska, N. V. Pogorelova, V. V. Vashchenko, Dispersion and aggregation of quantum dots in polymer-inorganic hybrid films, Thin Solid Films 537( 2013)226-230. 
23. L. C. Chen, Y. T. Chang, C. H. Tien, Y. Chun Yeh, Z. L. Tseng, K. L. Lee, H. C. Kuo, Red Light-Emitting Diodes with All-Inorganic $\mathrm{CsPbl}_{3}$ /TOPO Composite Nanowires Color Conversion Films, Nanoscale Res. Lett. 15(2020)216.

24. I, L. Braly, D. W. deQuilettes, L. M. Pazos-Outón, S. Burke, M. E. Ziffer, D. S. Ginger, H. W. Hillhouse, Hybrid perovskite films approaching the radiative limit with over $90 \%$ photoluminescence quantum efficiency, Nat. Photon. 12(2018)355-361.

25. C. Pothiklang, K. Hongsith, P. Ruankham, S. Choopun, Synthesis of Perovskite Film by Using Lead Nitrate as Precursor for Perovskite Solar Cell Applications, Mater. Today Proc. 17(2019)1224-1230.

26. T. Y. Hsieh, T. C. Wei, K. L. Wu, M. Ikegami, T. Miyasaka, Efficient perovskite solar cells fabricated using an aqueous lead nitrate precursor, Chem. Commun. 51(2015)13294-13297.

27. K. L. Wang, X. M. Lia, Y. H. Lou, M, Li, Z. K. Wang, CsPbBrl 2 perovskites with low energy loss for highperformance indoor and outdoor photovoltaics, Sci. Bulletin, 66(2021)347-353.

28. G. Eperon, G. Paterno, R. Sutton, A. Zampetti, A. A. Haghighirad, F. Cacialli, H. J. Snaith, Inorganic cesium lead iodide perovskite solar cells, J. Mater. Chem. A, 3(2015)19688-19695.

29. G. H. Xing, N. Mathews, S. S. Lim, N. Yantara, X. F. Liu, D. Sabba, M. Grätzel, S. Mhaisalkar, T. C. Sum, Low-temperature solution-processed wavelength-tunable perovskites for lasing, Nat. Mater., 13(2014)476-480.

30. Y. Q. Liu, L. K. Ono, Y. B. Qi, Organic additive engineering toward efficient perovskite light-emitting diodes, InfoMat 2(2020)1095-1108.

31. M. Zhang, F. Yuan, W. Zhao, B. Jiao, C. X. Ran, W. W. Zhang, Z. X. Wu, High performance organo-lead halide perovskite light-emitting diodes via surface passivation of phenethylamine, Organic Electron. 60(2018)57-63.

32. X. Cheng, C. J. Qi, W. Ding, J. W. Lu, X. M. Mo, Y. L. Zhou, T. Lin, X. M. Tao, H. M. Chen, Y. F. Ouyang, Boosted electroluminescence of perovskite light-emitting diodes by pinhole passivation with insulating polymer, J. Phys. D: Appl. Phys. 51 (2018)405103.

\section{Figures}



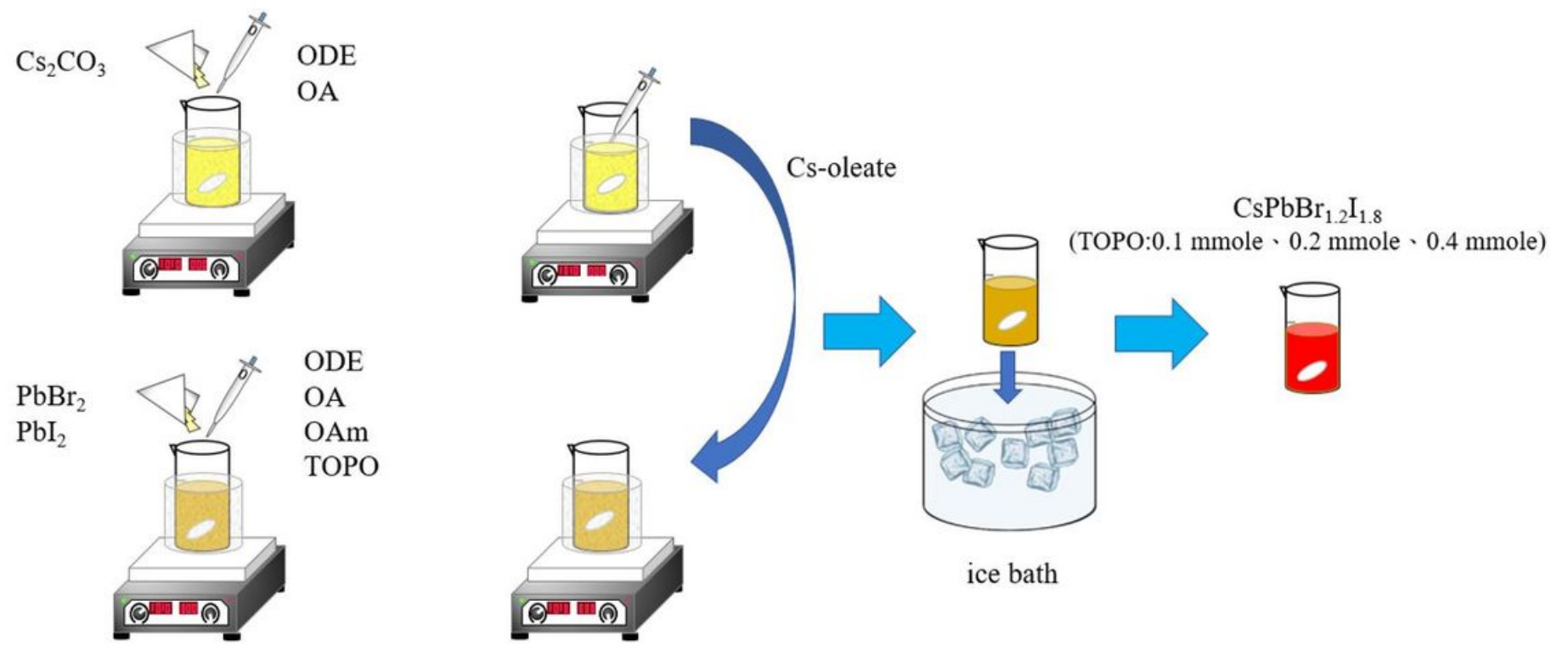

Figure 1

Process flowchart of CsPbBr1.211.8:TOPO perovskite quantum dots (QDs) precursor.

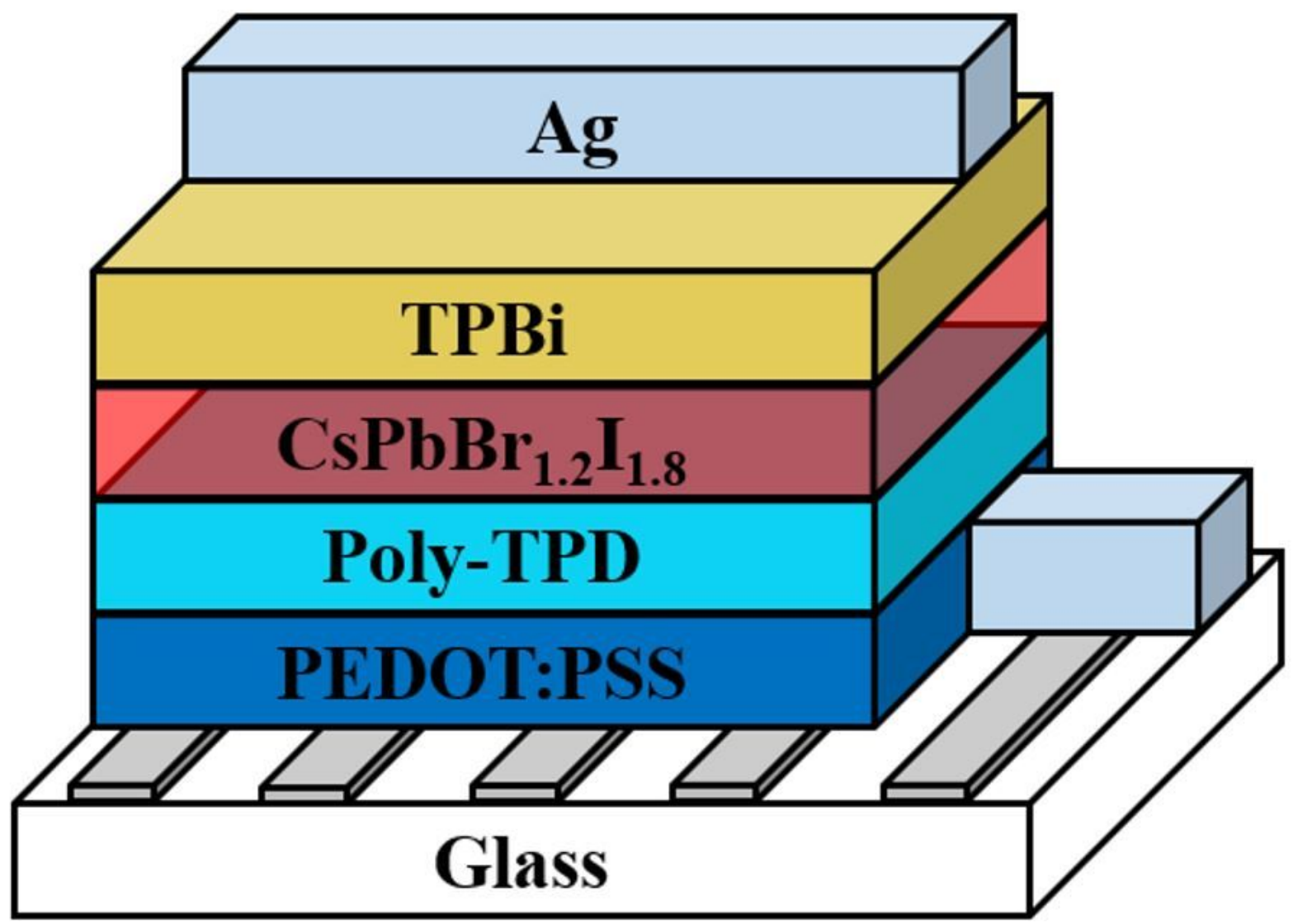

Figure 2 
Diagram of $\mathrm{CsPbBr} 1.211 .8$ perovskite red LED structure.
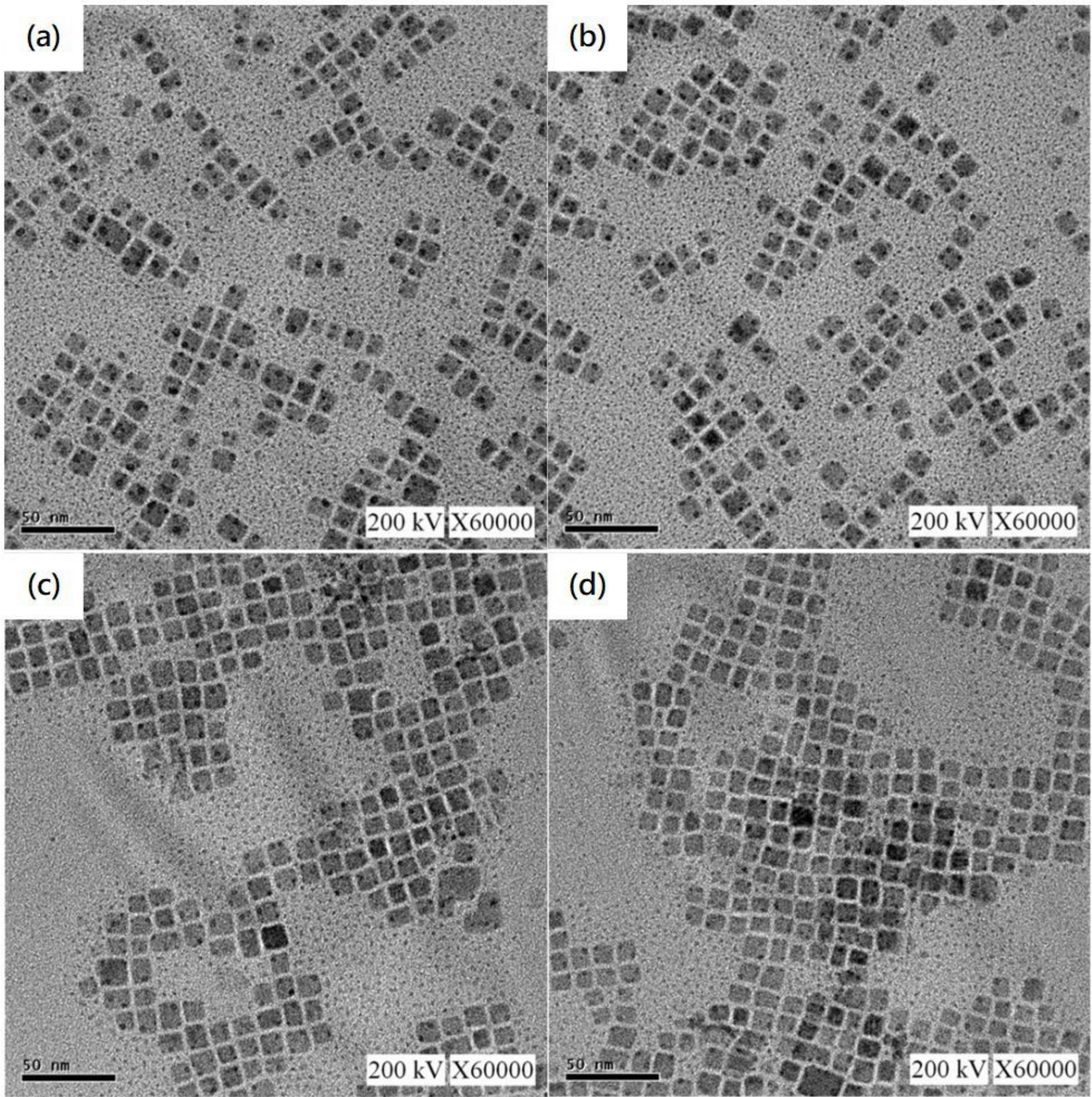

(d)

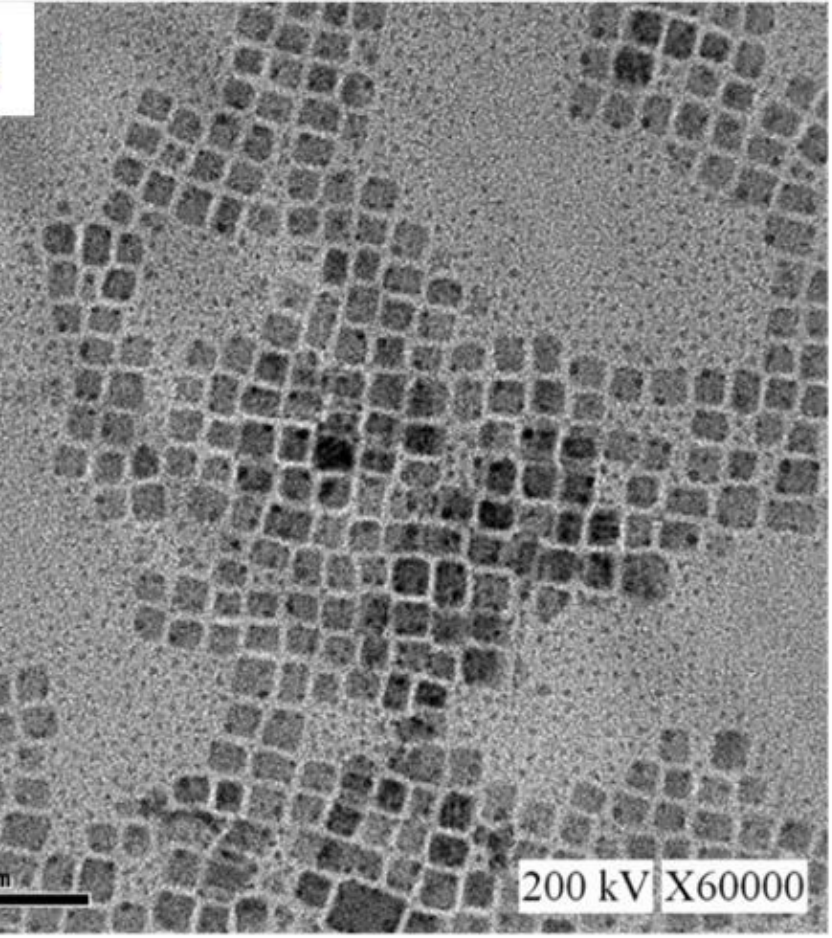

\section{Figure 3}

TEM images of CsPbBr1.211.8 QDs mixed with (a) 0, (b) 0.1 mmole, (c) 0.2 mmolw, and (d) 0.4 mmole TOPO. 
(a)

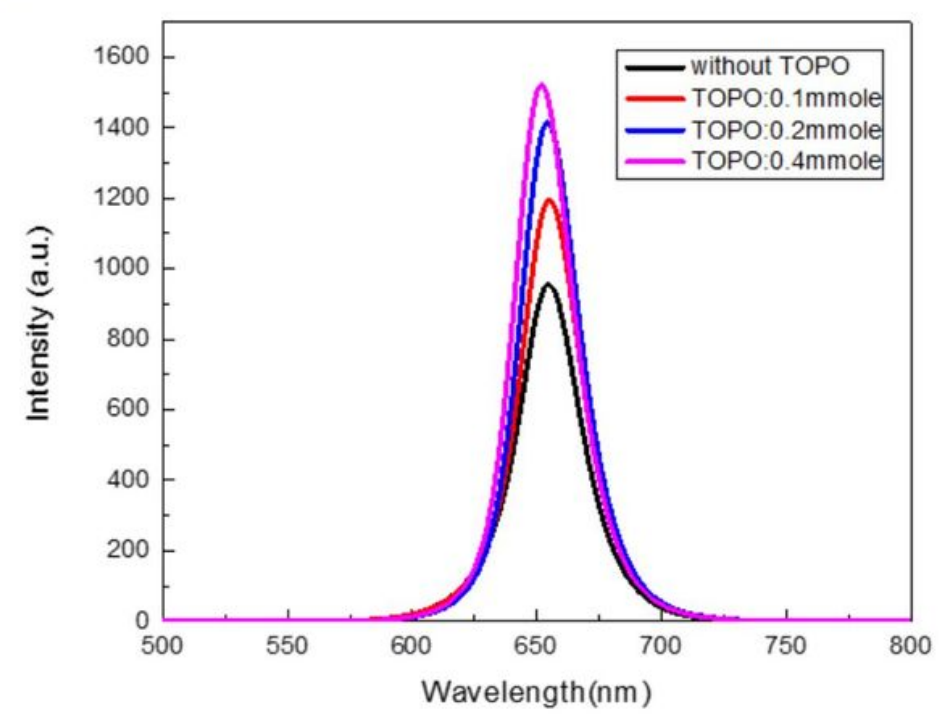

(b)

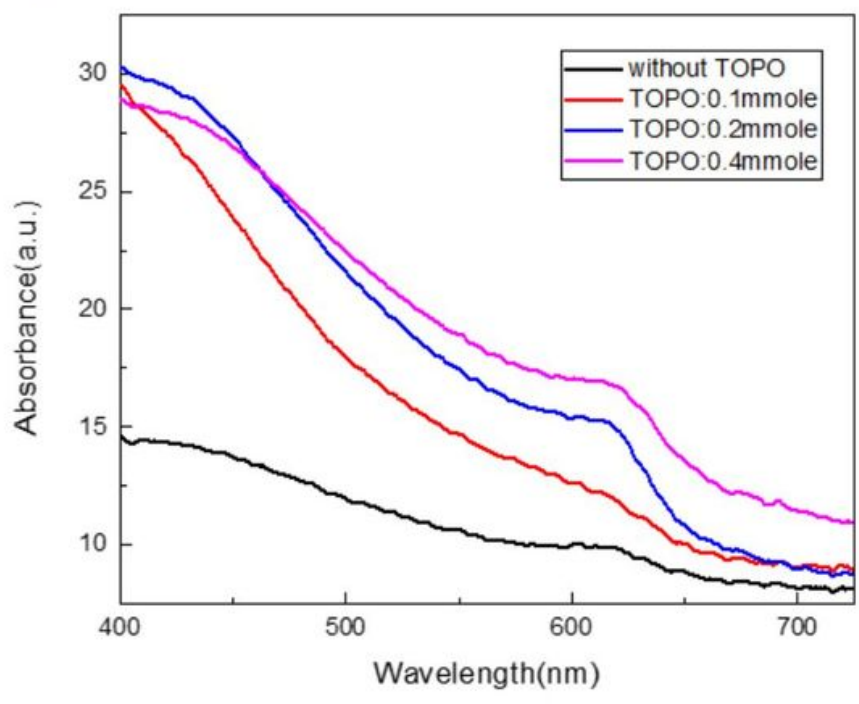

Figure 4

Photoluminescence and absorbance spectra of CsPbBr1.211.8 mixed with various concentration of TOPO. 
(a)

(b)

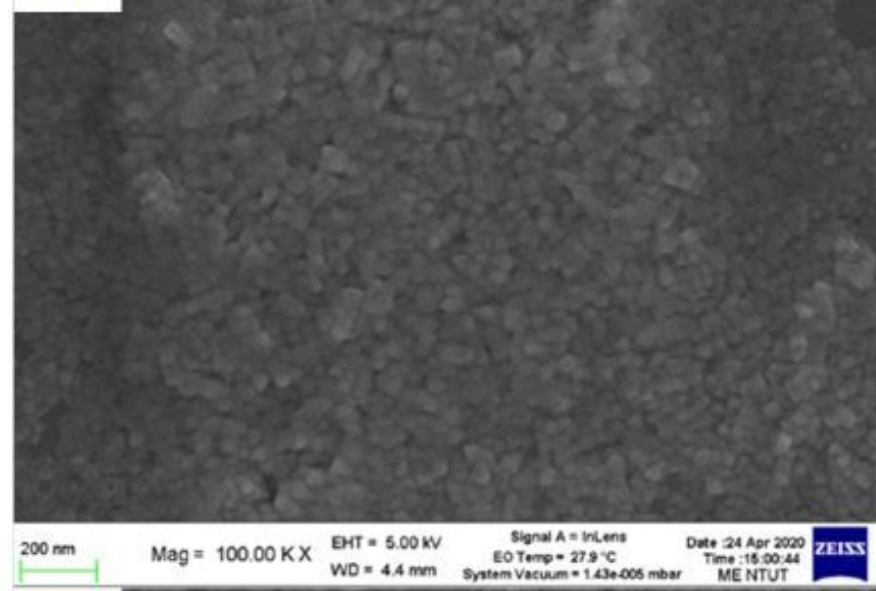

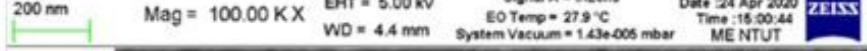

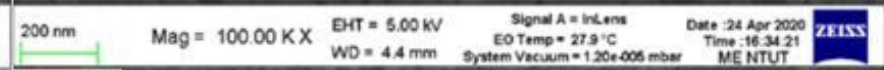

(c)

(d)
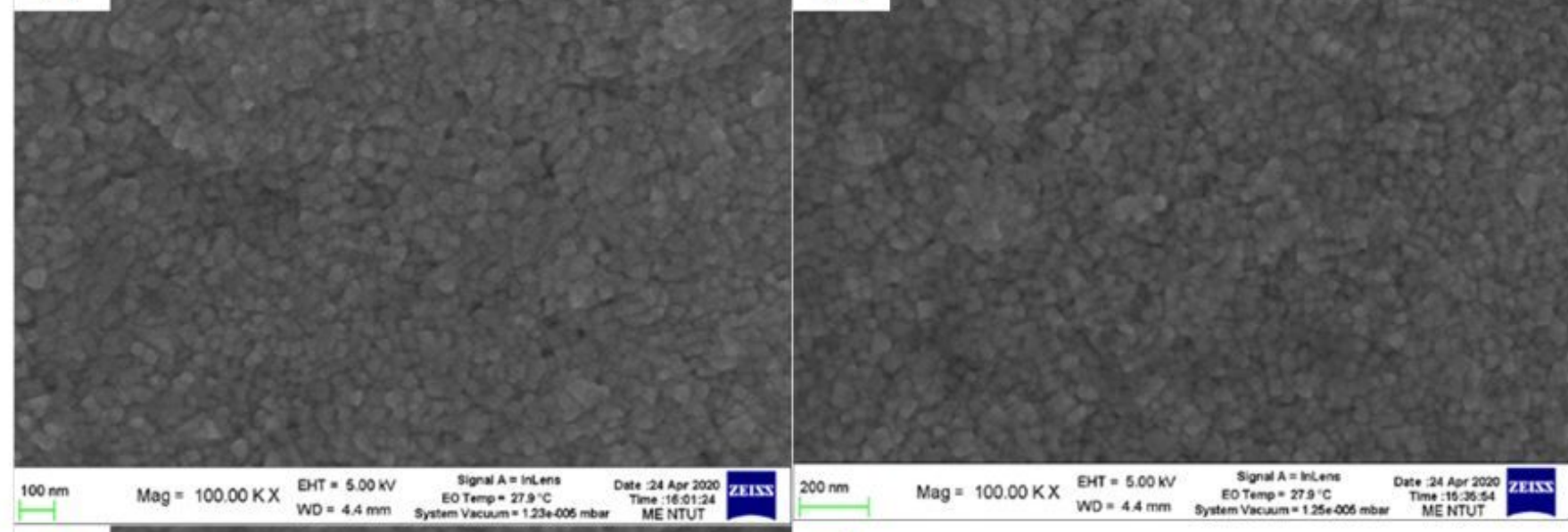

(e)

(f)
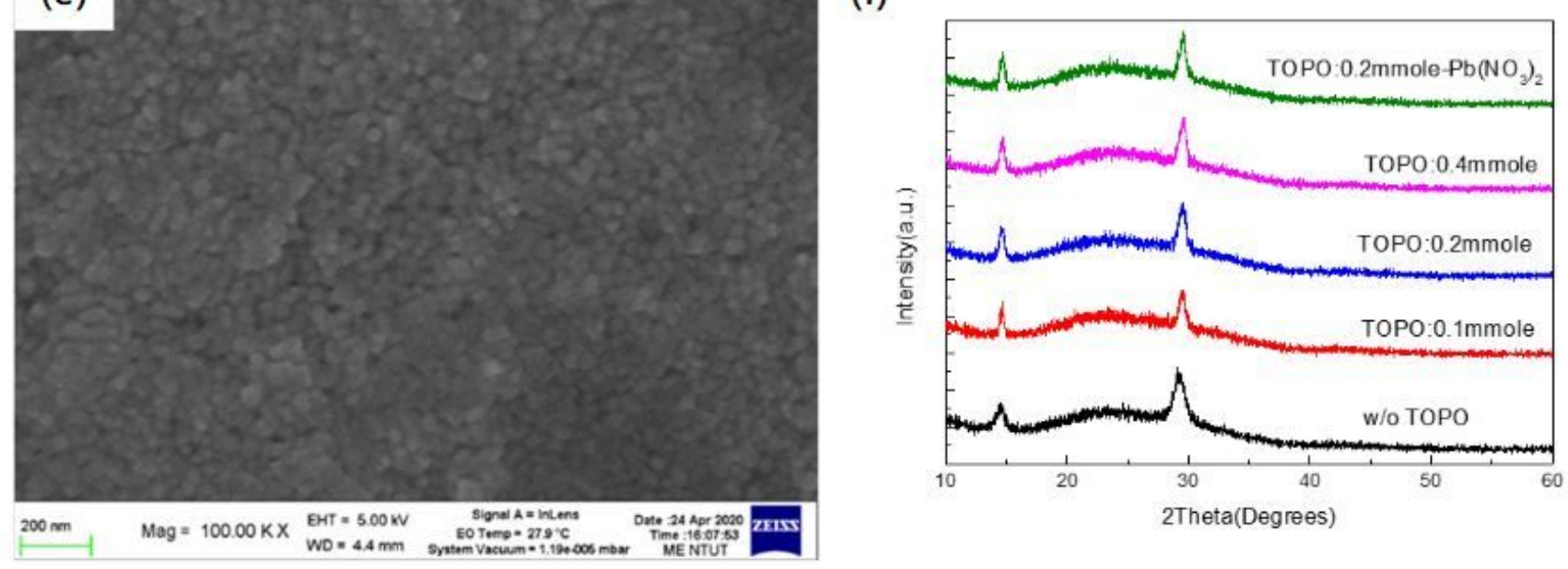

\section{Figure 5}

Top-view SEM images and XRD pattern. 


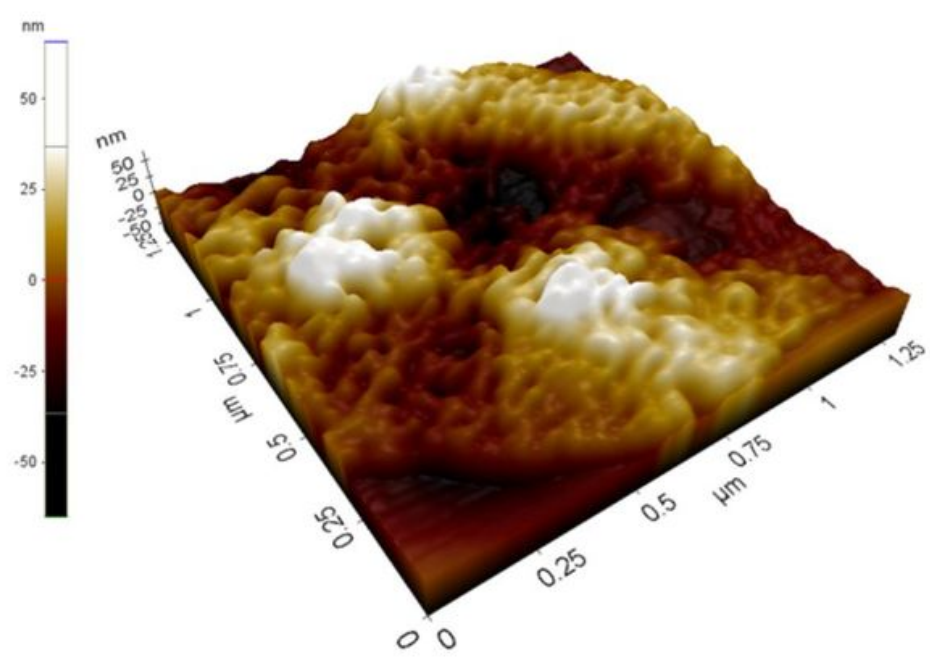

(a)

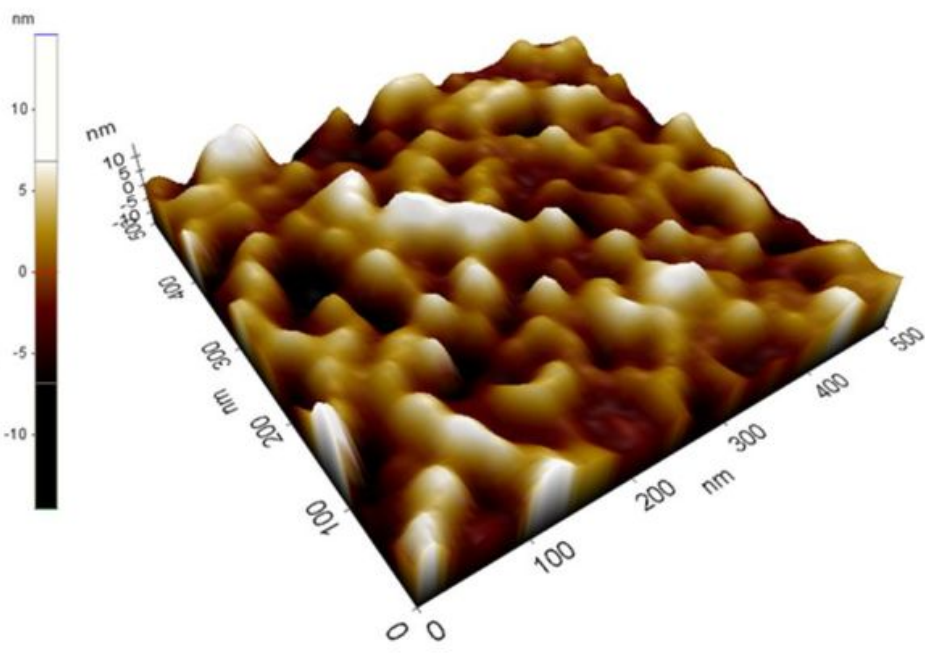

(b)

\section{Figure 6}

AFM images of CsPbBr1.2I1.8 films with (a) TOPO film and (b) TOPO-Pb(NO3)2.

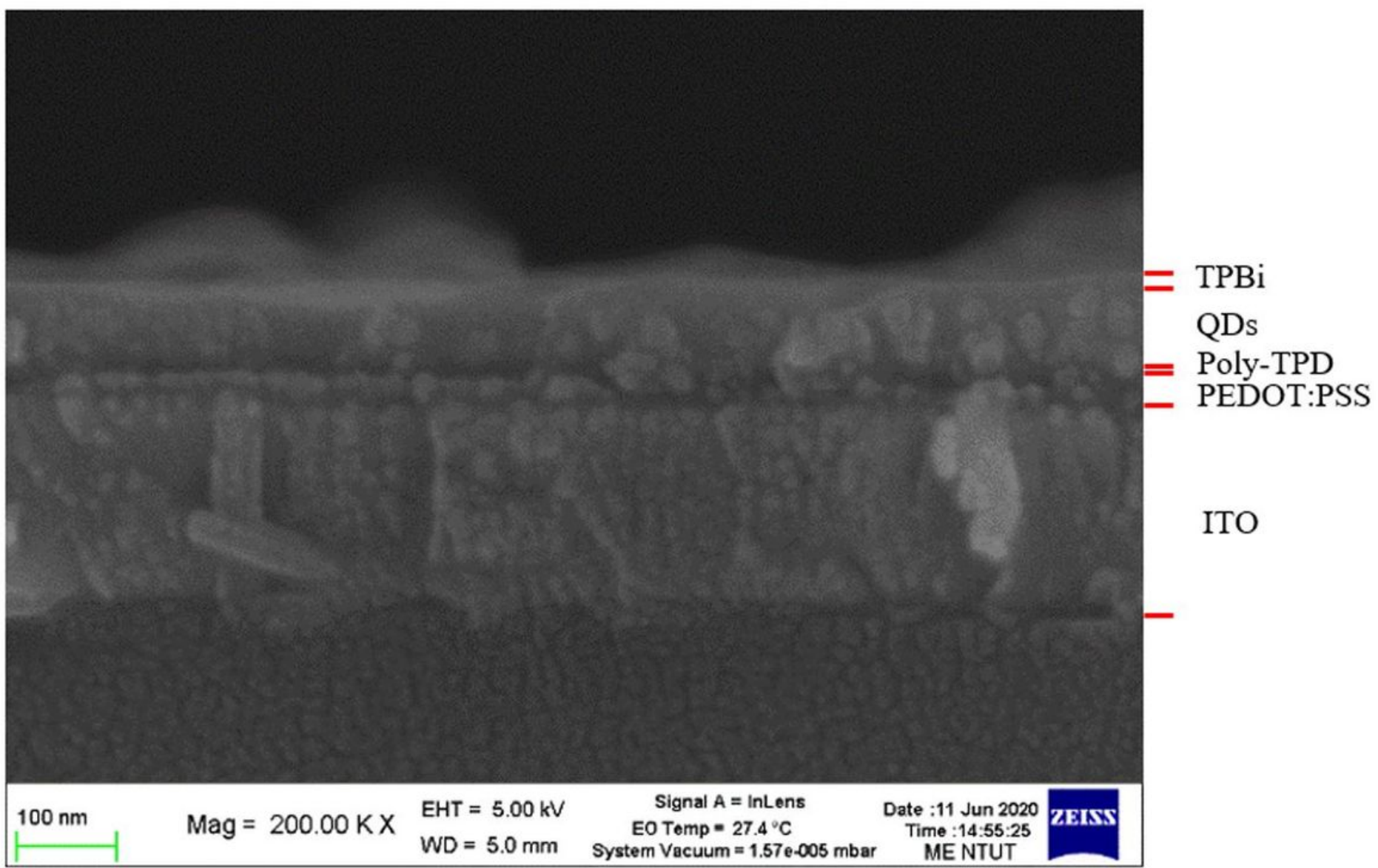

Figure 7 
Cross-sectional SEM image of perovskite CsPbBr1.211.8 QD LED.

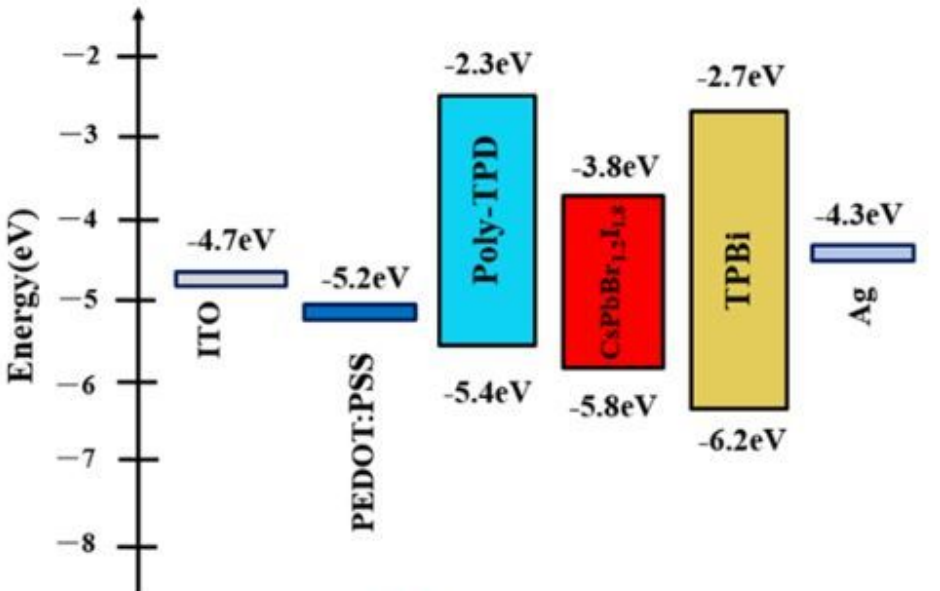

(a)

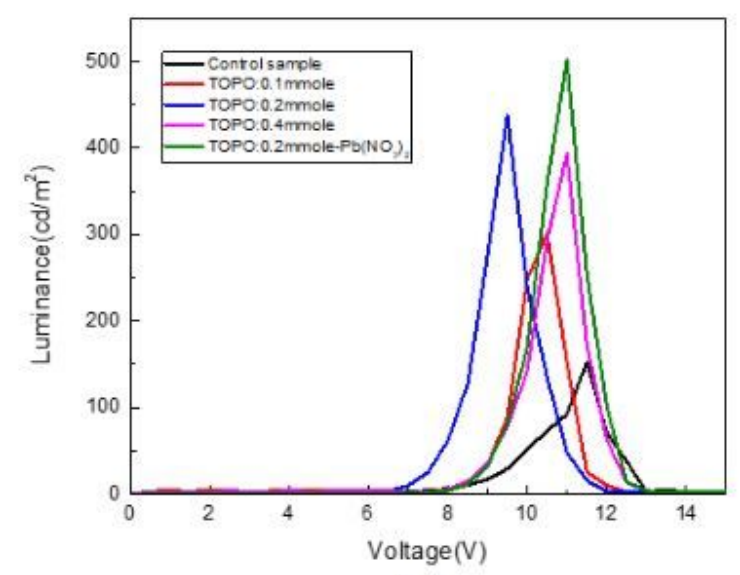

(c)

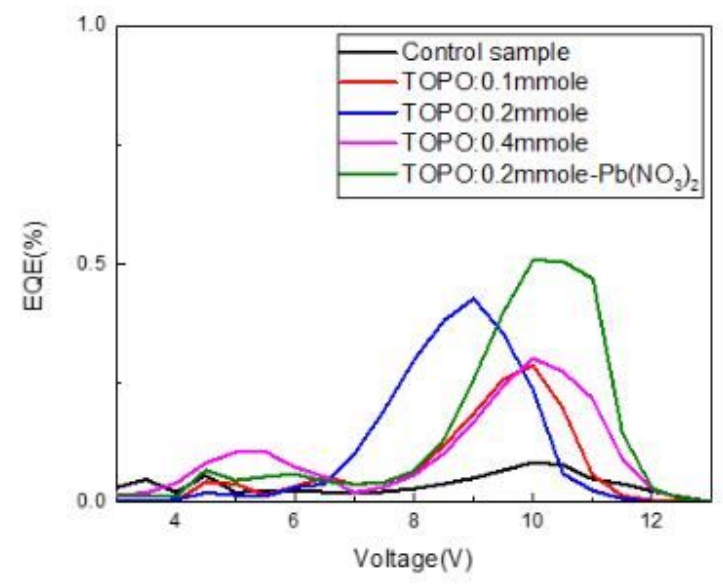

(e)

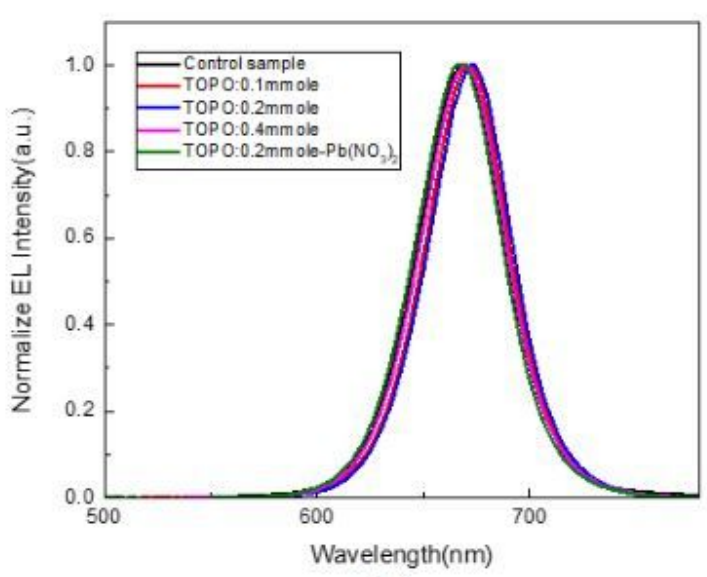

(b)

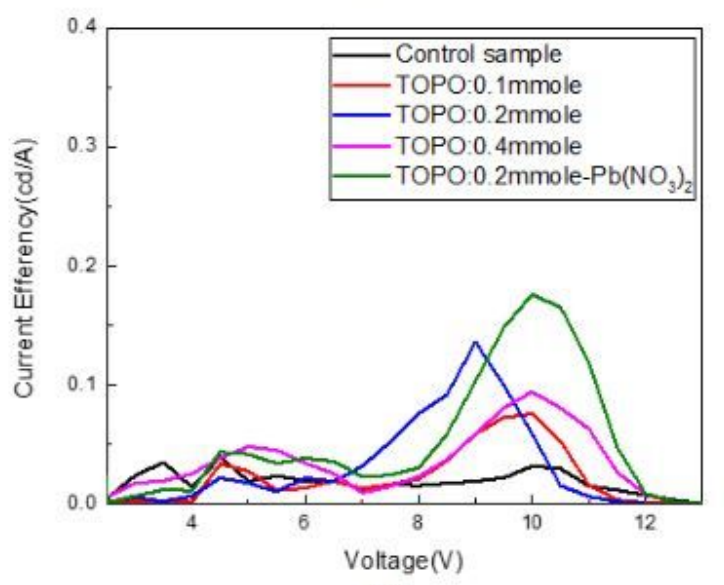

(d)

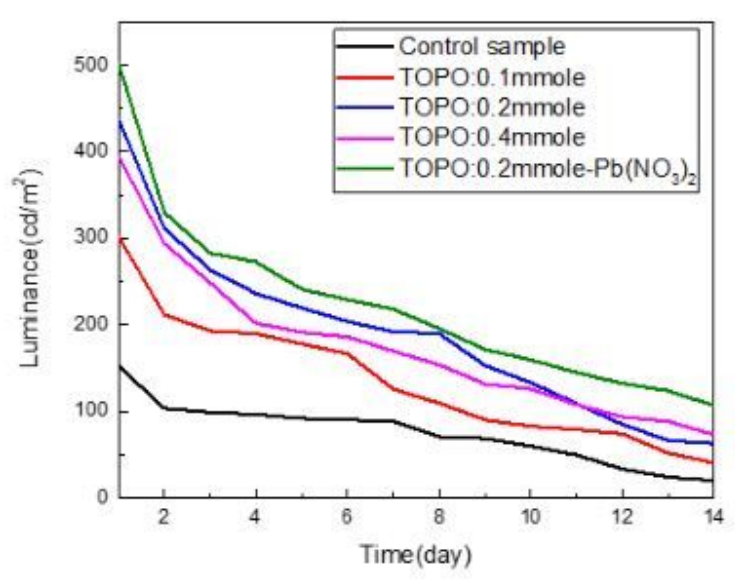

(f)

\section{Figure 8}

Perovskite CsPbBr1.211.8 QD LED device performance: (a) Band gap structure, (b) normalized EL spectra, (c) luminance characteristic, (d) current density characteristics, (e) external quantum efficiency (EQE), and (f) aging time results. 


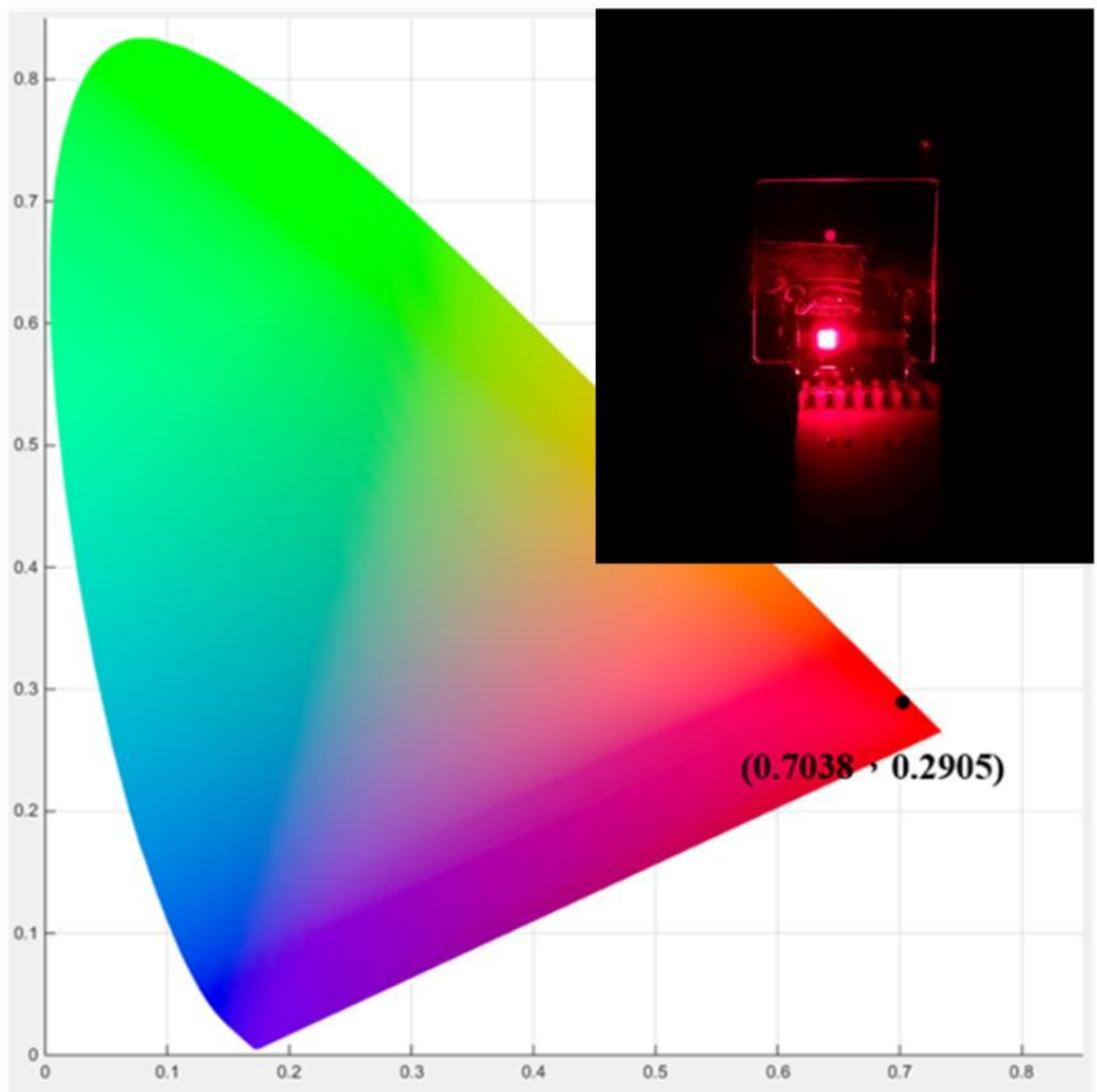

Figure 9

CIE chromaticity diagram of $\mathrm{CsPbBr} 1.211 .8:(\mathrm{TOPO}, \mathrm{Pb}(\mathrm{NO}) 2)$. The inset is the photo with $10 \mathrm{~V}$ bias in the dark. 